\title{
Ocio y recreación en América Latina: conceptos, abordajes y posibilidades de resignificación ${ }^{1}$
}

\author{
Rodrigo Elizalde* \\ Christianne Gomes*
}

\begin{abstract}
Resumen: Este artículo fue elaborado a partir de una investigación bibliográfica y tiene como objetivos analizar lo que significa un concepto; presentar los dos principales abordajes desde donde son entendidos el ocio y la recreación en América Latina, ampliando las posibilidades de resignificación de estos conceptos; y discutir las alternativas que estos conceptos -desde una nueva perspectiva- puedan aportar en la construcción de sociedades participativas, solidarias y sustentables. A modo de conclusión se destaca que la mayoría de las concepciones de ocio y de recreación, difundidos en Latinoamérica, fueron formuladas en otros contextos, mostrándose insuficientes e inapropiados frente a las problemáticas, contradicciones y potencialidades de esta región. Por esto, se requieren siempre nuevas lecturas y resignificaciones. A su vez, al entender el ocio como una dimensión de la cultura, se esboza la necesidad de promover una educación crítica/creativa por y para un ocio contrahegemónico, que rescate y valore la diversidad cultural como uno de los elementos decisivos para la transformación social.

Palabras clave: Conceptos; Ocio; Recreación; América Latina.
\end{abstract}

\section{Leisure and recreation in Latin America: concepts, approaches and possibilities of resignificance}

\begin{abstract}
This article was compiled from a bibliographic review and aims to: analyze what a concept is; present the two main approaches by which leisure and recreation are understood in Latin America, expanding thus the possibilities for new meanings to these concepts; and discuss the alternatives that these concepts -from a new perspective- can provide to the construction of participative, solidary and sustainable societies. In conclusion, it's emphasized that most of the concepts of leisure and recreation widespread in Latin America, were formulated in other contexts, showing to be insufficient and inappropriate to the problems, contradictions and potentialities of this region. That is why they need new approaches and resignificances. Understanding leisure as a dimension of culture outlines the need to promote a critical/creative education by and for a non-hegemonic leisure, which rescues and appreciates cultural diversity as one of the key elements for social transformation.
\end{abstract}

Key words: Concepts; Leisure; Recreation; Latin America.

\section{Lazer e Recreação na América Latina: conceitos, abordagens e possibilidades de ressignificação}

Resumo: Este artigo foi elaborado a partir de uma revisão da literatura e tem como objetivos analisar o que significa um conceito; apresentar as duas principais abordagens a partir das quais o lazer e a recreação são entendidos na América Latina, ampliando as possibilidades de ressignificação desses conceitos; e discutir as alternativas para que esses temas, a partir de uma nova perspectiva, contribuam com a construção de sociedades participativas, solidárias e sustentáveis. As conclusões do texto evidenciam que a maioria dos conceitos de lazer e de recreação difundidos na América Latina foram formulados em outros contextos, revelando-se insuficientes e inadequados diante dos problemas, contradições e potencialidades da região. Por essa razão, requerem sempre novas interpretações e ressignificações. Por sua vez, ao entender o lazer como uma dimensão da cultura, o artigo aponta a necessidade de promover uma educação crítica e criativa para/pelo lazer contra-hegemônico, que resgate e valorize a diversidade cultural como um dos elementos decisivos para a transformação social.

Palavras-chave: Conceitos; Lazer; Recreação; América Latina.

Recibido: 28.04.2010

Aceptado: 30.06 .2010

\section{Introducción}

\footnotetext{
${ }^{1}$ Apoyo: $\mathrm{CNPq} / \mathrm{FAPEMIG}$
} 
Este artículo fue basado en una investigación bibliográfica y tiene como objetivos: (a) analizar lo que significa un concepto, identificando cuales son los elementos claves a tener en consideración en el proceso de conceptualización de una temática de estudio; (b) presentar los dos principales abordajes desde donde son entendidos el ocio y la recreación en América Latina, ampliando las posibilidades de resignificación de estos conceptos; y (c) discutir las alternativas que estos conceptos, desde una nueva perspectiva contrahegemónica, puedan aportar a la construcción de sociedades realmente participativas, solidarias y sustentables.

\section{¿Qué es un concepto?}

Esta pregunta fundamental es uno de los puntos de partida para lograr avanzar y calificar la discusión y el diálogo teórico-conceptual sobre el ocio y la recreación en Latinoamérica. En el ejercicio de aclarar los significados de un término generalmente consultamos, en un primer momento, los diccionarios. Mismo que la mayoría de los diccionarios sean basados en los saberes del llamado "sensu común", veamos lo que algunos de ellos nos dicen sobre la propia palabra "concepto".

El Diccionario de la Lengua Española (www.rae.es) revela que este término tiene varios significados. Las definiciones más cercanas de lo que interesa en este estudio son descritas al decir que la palabra "concepto" es una idea que concibe o forma el entendimiento; un pensamiento expresado con palabras; la opinión o el juicio sobre algo. Luego se refiere a la idea de "formar concepto", lo que es entendido como el determinar algo en la mente después de examinadas las circunstancias.

Los diccionarios de la lengua portuguesa también indican la existencia de varias acepciones para esta palabra. Según Ferreira (1999), "concepto" es una idea, o sea, una representación mental de algo que puede ser concreto o abstracto. Esta visión también es adoptada por Houaiss (2001). Para este autor, "concepto" es una representación mental de un objeto, que se muestra como un instrumento fundamental del pensamiento en su tarea de identificar, describir y clasificar los diferentes elementos y aspectos de la realidad.

Esta última idea está presente en el diccionario de filosofía de Abbagnano (1999). Para el autor, la función primera y fundamental del concepto es la misma del lenguaje, o sea, la comunicación. El autor agrega que un concepto es normalmente indicado por un nombre, pero él no es el nombre. De este modo, diferentes nombres pueden exprimir un mismo concepto. Es así que los conceptos nos ayudan a comprender y a comunicar, pero a su vez nos ayudan también a aclarar y a fijar los significados, permitiéndonos dialogar y construir entendimientos comunes sobre los fenómenos que observamos, estudiamos y con los cuales estamos involucrados. En síntesis, cuando expresamos un concepto, estamos indicando un cierto tipo de "especulación" o "representación" sobre la naturaleza, sobre la sociedad, sobre el ser humano y sobre sus prácticas.

Para Galuch y Sforni (2005) la formación de conceptos es un proceso, no es un resultado de transmisión de palabras o de definiciones que expresen la generalización comprendida en los conceptos. Por lo tanto, la formación de conceptos es el movimiento del pensamiento con oscilaciones constituidas de poco a poco, por el uso de las palabras, por combinaciones entre operaciones mentales, aislando atributos comunes entre objetos, abstrayendo determinados riesgos, simbolizando y llegando a una síntesis.

Agregado a lo expuesto, a continuación sistematizamos algunos aspectos claves de un concepto:

- Los conceptos son representaciones de la realidad material/inmaterial. El proceso mentalracional de sistematización de ideas por parte de un autor, o de varios autores, envuelve abstracciones que son influenciadas por varios elementos: comprensión de ser humano, visión de mundo, personalidad, historia de vida, valores, principios éticos y morales, proyectos políticos, etc. Es así que un concepto expresa la forma como cada uno ve y nombra los distintos fenómenos.

- Los conceptos son el mapa pero no el territorio. En tanto representaciones de la realidad, los conceptos nunca serán totalmente equivalentes a esa realidad que buscan expresar. El mapa siempre será una representación de una realidad concreta, por lo cual no se debe confundir las representaciones -los conceptos- con eso real que ellos buscan expresar. 
- Los conceptos deben ser contextualizados porque ellos no son universales. Es fundamental tener en cuenta que algunos conceptos son válidos para una determinada realidad y para algunos sistemas de ideas pero ellos no siempre podrán ser generalizados, ni entendidos como universales. Un concepto adquiere sentido en una producción (práctica/teórica); que adquiere su sentido en el conjunto de las visiones de su(s) autor(es), que participa de una determinada realidad contextual y así sucesivamente. Lo que puede ser valido en un contexto histórico, político y cultural, o dentro de un específico sistema teórico, en otras circunstancias o en otro contexto puede carecer de validez.

- Los conceptos son dinámicos. Un concepto puede ser válido y suficiente para explicar la realidad en un determinado tiempo/espacio histórico/social, pero cambiar sus significados de acuerdo con las intenciones de los sujetos que los producen y de los requerimientos de cada momento. Los sentidos de cada concepto son complejos, fluidos y están en constante transformación.

- Unido a lo anterior se verifica que, al igual que en la vida, todo concepto está en un estado de inacabamiento. Esto posibilita una constante transformación y profundización, pero a la vez expresa lo parcial y limitado de nuestras representaciones del mundo, al ser construcciones humanas, y por esto en muchos casos teñidas por el error y la ilusión. En tanto seres humanos somos inacabados y estamos en un constante proceso de formación y reformación. Lo mismo ocurre con el proceso de conceptualización.

- Los conceptos no son neutrales, tampoco totalmente objetivos. Toda explicación, interpretación y forma de entender la realidad estará teñida por visiones de mundo, entiéndase cosmovisiones y paradigmas, presentes de forma explícita o implícita y oculta, expresando una imposibilidad de neutralidad. Entonces la búsqueda de imparcialidad y objetividad será solo un deseo, esto es una pretensión, que no podrá concretarse del todo. Tener presente esta imposibilidad del conocimiento humano es un primer paso para empezar a ser un poco más humilde al elaborar nuestras teorías.

- Un mismo concepto puede generar diversas interpretaciones. De este modo, un concepto puede ser conceptualizado por varios autores con significados e intenciones distintas, según las visiones de cada uno de ellos y su contexto específico. Por un lado, la multiplicidad de sentidos que un mismo concepto puede tener es una fuente rica de aprendizaje. Por otro lado, puede ser también una fuente de confusión, como es común con relación al empleo de los conceptos de ocio, recreación y tiempo libre en América Latina, muchas veces tratados de forma vaga y poco rigurosa.

Por todo lo recién planteado, postulamos que requerimos un profundo cambio en la forma de elaborar conocimientos, reconociendo las limitaciones que cualquier concepto posee, pero a la vez abriéndonos a correr el riesgo de formular nuevas perspectivas desde donde comprender lo complejo de la actualidad. Siendo así, deberemos estar atentos frente a la relación que se establece entre lo conocido y lo desconocido, lo que puede ser expresado en la siguiente explicación de Morin (1988): Se puede comer sin conocer las leyes de la digestión, respirar sin conocer las leyes de la respiración, pensar sin conocer la naturaleza del pensamiento. Pero mientras la asfixia y la intoxicación se dejan sentir inmediatamente en la respiración y en la digestión, lo propio del error y la ilusión es no manifestarse como error e ilusión. Es así que vemos como actualmente el mito adquirió la forma de la razón y la ideología se ha disfrazado de ciencia.

Entendemos que esto, en parte, es lo que ha ocurrido en la forma en que han sido formulados los conceptos de ocio y de recreación en América Latina.

\section{Relectura de los conceptos de recreación y de ocio}

¿Desde cuándo/dónde fueron elaborados y en que consisten las principales concepciones de ocio y de recreación difundidas en América Latina?

Un análisis de artículos, libros y otras publicaciones de autores latinoamericanos que producen conocimientos sobre el ocio y sobre la recreación evidencia que son múltiples los conceptos y los significados adoptados en nuestra región. América Latina está constituida por más de 30 naciones hoy 
independientes que conviven con otros estados dependientes, sobretodo en la zona caribeña, que aún siguen siendo colonias de los países más ricos del mundo. La colonización económica, política y cultural de nuestros territorios es una de las cicatrices más profundas y abiertas de América Latina. Colonización, decretada o camuflada, que por varios siglos tuvo, y tiene, su existencia marcada por la explotación de los pueblos y de las riquezas con la finalidad de atender los intereses y las necesidades de los países ricos del "Norte" (geo-económico-político) del mudo.

Dominación cultural que se expresa también hasta la actualidad a través de variadas formas. Siendo la "colonialidad del saber" una de ellas, la que a través de una noción de universalidad a partir de la experiencia particular de la historia europea, realiza la lectura de la totalidad del tiempo y espacio humano desde los puntos de vistas de esas particularidades, instituyéndose así una universalidad radicalmente excluyente (Castro-Gómez, 2000; Lander, 2000).

Frente a lo anterior se hace necesario destacar que algo similar ocurre con la influencia norteamericana, desde los Estados Unidos, que fue y es muy fuerte a nivel social en la visión de mundo y concepciones económicas, políticas, educativas y culturales en Latinoamérica. Llegando a ser, el "imperio del norte", un modelo de sociedad al que debíamos de acceder, para así cumplir con el anhelado (y falaz) sueño de ser un país desarrollado. Por esta vía se logró imponer un modelo de sociedad capitalista y un ideal de estilo de vida (forma de producción y consumo), lo cual abarcó varias expresiones culturales y sociales, incluyendo al ocio (Elizalde, 2010).

Todo esto es decisivo al analizar los conceptos de ocio y recreación, los cuales son múltiples y variados. Aclaramos que no tenemos la intención de hacer aquí un análisis puntual de cada uno de ellos. Lo que si se considera es que de forma general, más allá de las posibles diferencias que marcan cada definición, en Latinoamérica podemos constatar la presencia de dos grandes abordajes en los cuales se puede agrupar los variados entendimientos de ocio y de recreación. Más allá de los conceptos específicos de ocio y de recreación, hay todo un contexto de producción de conocimientos que necesita ser conocido y analizado. Teniendo en cuenta estos aspectos, los dos abordajes aquí señalados serán presentados a continuación.

\section{Primer abordaje: El enfoque de la recreación}

Este abordaje remite, en sus orígenes, a los Estados Unidos de América (EE.UU.). Para comprender la recreación en cuanto fenómeno social/educativo, tenemos que volver al final del siglo XIX, cuando ocurrió una amplia difusión del movimiento norte-americano conocido como "recreacionismo". Este movimiento propició la sistematización de conocimientos y metodologías de intervención para niños, jóvenes y adultos. Estos conocimientos eran pautados en la sistemática de la recreación dirigida, que fomentó la creación de espacios propios para la práctica de actividades recreativas consideradas saludables, higiénicas, moralmente válidas, productivas y vinculadas a la ideología del "progreso". Fueron así creados los playgrounds, que posteriormente servirán de modelo para los centros de recreación, plazas de deportes y jardines de recreo reproducidos en varios países latinoamericanos.

Buscando aportes en los conocimientos producidos en Europa, el primer playground en EE.UU., el año1885, fue inspirado en los parques infantiles de Berlín, Alemania. En 1925 ya existían 8.115 centros de recreación, siendo creados 635 apenas en el año 1924, cuando 80 ciudades realizaron 123 campamentos de verano para niños y jóvenes. La gran repercusión del recreacionismo inauguró un nuevo estilo de vida en los EE.UU., fomentando nuevas frentes de formación y de actuación profesional. Con la ayuda de instituciones como a Young Men's Christian Association (YMCA) - Asociación Cristiana de Jóvenes (ACJ) en la lengua española -, en las primeras décadas del siglo XX el recreacionismo fue difundido rápidamente por varios países, alcanzando especialmente América Latina (Gomes, 2003).

En Brasil, los registros del brasileño Frederico Gaelzer son una de las evidencias de esta afirmación. Con el apoyo de la ACJ de Porto Alegre/Brasil, Gaelzer pasó un largo período en los EE.UU. (1919-1925) para formarse y calificarse en educación física, deporte y recreación. En el Relatorio escrito por Gaelzer y enviado a los Directores de la ACJ de su ciudad, con fecha de 16/09/1919, el autor resalta que mientras el mundo estaba en guerra, los 800 participantes de los cursos impartidos por la propia YMCA, en Chicago, estaban en paz, unidos y con un mismo ideal compartido por todos. Los 
participantes de estos cursos eran de 25 nacionalidades diferentes, siendo todos poseedores de la misma moral "pura y sana" requerida por la YMCA (Gomes, 2003; Gomes, Pinto, 2009).

Probablemente, muchos de estos participantes eran latinoamericanos, contribuyendo de forma decisiva para la difusión de los conceptos de recreación por varios países de América Latina. Obviamente, muchas prácticas recreativas como los juegos y otras formas de diversión ya existían, pero en ese momento fueron sistematizadas como parte integrante de un concepto de recreación elaborado en los EE. UU.

Desde un punto de vista conceptual, los principales significados incorporados por la recreación en este contexto fueron: (a) actividades placenteras con potencial educativo, destacándose el juego infantil organizado, las actividades deportivas o pre-deportivas; (b) disposición física y mental para la práctica de alguna actividad placentera, (c) contenido y metodología de trabajo para el área de educación física. Teniendo en cuenta estos aspectos, el principal concepto de recreación sistematizado y difundido en distintos países de América Latina se mezcla con la idea de actividad.

Por cierto, existen otros conceptos de recreación que intentan ir más allá de la práctica de actividades. Pero esta forma de entender la recreación como sinónimo de actividades placenteras con potencial educativo, desde el punto de vista de este artículo, es la más difundida en América Latina desde las primeras décadas del siglo XX, lo que no puede ser desconsiderado. Paradojalmente, en muchos casos los discursos conceptuales sobre la recreación son más elaborados que sus prácticas, ya que no en raras ocasiones las implementaciones concretas no consiguen escapar del activismo, de un hacer por hacer, carente de los contenidos educativos que se postulan.

Entonces, históricamente, en un primer momento fueron principalmente las ideas y perspectivas norteamericanas las que posibilitaron la formulación del concepto de recreación, palabra que corresponde a los términos recreation en inglés y recreação en portugués, siendo inexistente en la lengua francesa.

Es necesario aclarar que, en sus orígenes norteamericanos, el concepto de recreación fue visto como una estrategia educativa esencial para promover, sutilmente, el control social. En este proceso, fue ampliamente difundida la idea que la recreación podría llenar, racionalmente, el tiempo vago u ocioso con actividades consideradas útiles y saludables desde el ponto de vista físico, higiénico, moral y social. Con esto, la recreación dirigida fue considerada esencial para la formación de valores, hábitos y actitudes a ser consolidados, moralmente validas y educativamente útiles para el progreso de las sociedades modernas. En un primer momento el desarrollo de eventos, políticas, programas y proyectos recreativos fueron, y muchas veces aún lo son, direccionados principalmente a grupos sociales en situación de riesgo o de vulnerabilidad social, buscando la reducción de conflictos sociales y de la delincuencia, la manutención de la paz y armonía social, y la ocupación positiva y productiva del potencial tiempo ocioso.

Además de permitir llenar las horas vagas de niños, jóvenes, trabajadores adultos y ancianos, colaborando con la constitución de cuerpos disciplinados, obedientes, aptos, productivos y vigorosos. Desde esta perspectiva, la recreación acaba, en muchas ocasiones, siendo utilizada para olvidar los problemas generados por la lógica excluyente que impera en las realidades latinoamericanas. A su vez, las varias acepciones de recreación son fundamentadas en el área de pedagogía, la psicología y, sobre todo, en la educación física. Esta última área, junto al deporte, es la más asociada a la recreación tanto en la vida cotidiana como en los estudios, cursos, propuestas de formación sobre el tema, campo de actuación profesional y en el ámbito de las políticas públicas latinoamericanas.

Añadido a lo anterior, se verifica una cierta confusión entre los términos recreación y ocio, dificultad expresada por Ried, Leiva y Elizalde (2009), Suárez (2009) y Osorio (2009). Ambos conceptos conviven juntos en muchos países latinoamericanos, pero muchas veces existe también una profunda confusión, como puede ser verificado en el libro publicado hace poco que lleva como título: "Lazer na America Latina/Tiempo libre, ocio y recreación en Latinoamérica" (Gomes et al, 2009). Esta situación indica la relevancia de hacer la siguiente pregunta: Recreación y ocio ¿Son lo mismo?

\section{Segundo abordaje: EI enfoque del ocio}

En los estudios sobre el ocio es posible verificar que este abordaje remite, generalmente, a la antigua Grecia clásica o a la modernidad Europea. Lo que posibilitó la sistematización del concepto de 
ocio, una palabra que hoy, según algunos autores (con los cuales estamos de acuerdo), en la lengua española corresponde, o al menos se acerca, a los términos leisure en inglés ${ }^{1}$, loisir en francés ${ }^{2}$ y lazer en portugués (Gomes, Elizalde, 2009). Antes de proseguir, es importante comprender algunas de las ideas que los autores desarrollan para contextualizar sus conceptos de ocio.

Para algunos autores (De Grazia, 1966), el concepto de ocio fue asociado, al principio, al término griego skholé - que valoraba la contemplación, la meditación y la reflexión - y al vocablo romano otium, que además de reforzar el ocio griego en el caso de las elites de Roma, fue utilizado para designar las diversiones y los espectáculos organizados para el público masivo, haciendo referencia a la tradicional expresión "pan y circo" que evidencia el potencial muchas veces alienante del ocio.

Luego, en el transcurso de los siglos llamados medievales, a medida que la iglesia difundía el cristianismo, una nueva moral pasa a definir otros sentidos para la concepción de ocio. De esta forma el ocio asumió nuevos significados marcados por una moral católica, donde la búsqueda de la salvación del alma mediante la negación y rechazo de los placeres mundanos, al ser esto una expresión clara del pecado, marcó fuertemente este contexto y período histórico.

El control por parte de la iglesia se tornó más evidente durante la inquisición, dramático proceso que marcó profundamente la vida de los pueblos por varios siglos. La iglesia procuró reforzar su poder y unidad de forma represiva, condenando a la hoguera a quienes practicaran supuestas herejías, como fiestas profanas, carnavales, juegos, encuentros de música, teatro y poesía, entre otras formas de diversión. Las investigaciones del historiador Roger Chartier revelan que las fiestas y reuniones campesinas, además de llenas de condenaciones eclesiásticas, eran siempre mencionadas como lugar de trabajo común, de juego y danza, de risa y diversión, de cuentos y cantos, de confesiones, rumores y chismes. Por lo cual, como esas reuniones eran consideradas ilícitas, "sucias y malditas", debían ser evitadas (Gomes, 2008).

Siendo así, el discurso hegemónico hizo que muchas experiencias culturales de ocio, en este contexto histórico, se cargaran de valores morales que acabaron siendo esenciales para el mundo del trabajo, sobre todo en la llamada modernidad. En este nuevo período, la forma de percibir al ocio fue marcada pricipalmente por una visión negativa, lo que pudo haber surgido, en parte, producto de la influencia del protestantismo, al ver las vivencias de ocio como un vicio y la educación como un medio moralizante para el trabajo (Requixa, 1977). La visión protestante destacó la ética del trabajo como bien supremo, rechazó al ocio por considerarlo como una potencial amenaza para el "espíritu" de base del modelo de producción capitalista. De este modo, el sentido de ocio como una manifestación cultural basada en la meditación, la reflexión y la contemplación, fue perdido, y así, el ocio fue rechazado y llenado de prejuicios (Elizalde, 2010).

Así, desde el siglo XIX el concepto de ocio está muy vinculado a las categorías trabajo y tiempo libre - concebidas desde una perspectiva sociológica. Por eso, la sociología es una importante área (pero no la única) que fundamenta las teorías y análisis desarrollados sobre la temática, principalmente por autores de Europa y de los Estados Unidos. Para muchos estudiosos, entre los cuales se destaca Dumazedier (1979), el ocio surgió en la modernidad europea en los siglos XVIII-XIX como fruto de la revolución industrial acontecida, en esa época, en los principales centros urbanos de Europa. Para él, el ocio se contrapone al trabajo y corresponde a una liberación periódica del trabajo en el fin del día, de la semana, del año y de la vida, cuando se alcanza la jubilación.

Independiente de que la ocurrencia histórica del ocio sea ubicada en la Grecia clásica o en la modernidad europea, es posible observar que Europa, con sus prácticas e instituciones es considerada, desde esta visión, como imprescindible y determinante para el "surgimiento" del ocio. Así, se perpetúa la idea de que existe una historia universal de modernidad y de ocio, una historia que ubica a Europa en una posición central, destacada y que debe ser tratada como válida para todo el mundo.

De esta forma, se instala una lógica evolutiva y lineal que define los tiempos, las historias, las culturas y las prácticas de todas las realidades, de todos los pueblos que, a su vez, deben anhelar el modelo occidental - moderno, urbano, industrial y capitalista- como el ideal a ser alcanzado para acceder al anhelado progreso.

Desde el siglo XX estas dos distintas interpretaciones sobre el origen historico del ocio han generado profundas polémicas cuando se busca hacer una contextualización histórica de este fenómeno. 
En general, ambas son ampliamente utilizadas en las teorías sobre el ocio que orientan y fundamentan los estudios sobre esta temática en varias partes del mundo, ejerciendo influencias significativas sobre los conocimientos difundidos en los distintos países de Latino América. Todas estas interpretaciones, aún cuando son dotadas de lógicas propias, se refieren a realidades específicas, pertinentes cuando se trata de Europa, por ejemplo. Pero ellas son inadecuadas e insuficientes, desde la perspectiva de este estudio, para discutir el ocio y la recreación en Latinoamérica. Esta región posee otras singularidades y otros marcos históricos, culturales, sociales, políticos y económicos. Todo esto demanda otras interpretaciones, abordajes, reflexiones y resignificaciones, así como la sistematización de otros saberes teórico-práticos que sean capaces de dialogar críticamente con las realidades latinoamericanas.

Además, estas interpretaciones son producciones teóricas que refuerzan el mito de la centralidad de Europa como referente privilegiado para la constitución del mundo, y sobre todo el llamado mundo occidental. Añadido a lo anterior, la idea de que occidente es el resultado de la secuencia helenística+romana+cristiana, a pesar de estar ampliamente difundida y naturalizada entre nosotros, es una idea equivocada, y una invención ideológica que presenta a la cultura griega como exclusivamente europea y occidental, tal como destaca Dussel (2000).

Ambas referencias utilizadas para contextualizar el "origen histórico" del ocio y la recreación refuerzan el mito de que existe una história única y universal. Refuerzan, además, la visión paradigmática de que la modernidad dependió únicamente de Europa para ser construida como una fase histórica al establecer y reconocer apenas fenómenos intra-europeos (entre los cuales se destacan la reforma, la ilustración y la revolución industrial) como punto de partida para la constitución de la llamada época moderna.

Las interpretaciones centralizadas en Europa excluyen la decisiva participación de otras realidades en un juego que envuelve, de manera desigual, varios componentes, dentro de los cuales los pueblos y culturas de otros continentes, tales como América Latina, África y Asia. Sabemos que la conquista del Atlántico y el desarrollo del capitalismo mercantil permitieron que los países colonizadores de Europa acumulasen una extraordinaria riqueza monetaria. Estos elementos generaron las condiciones históricas y sociales fundamentales para la constitución de la época moderna que, sin duda, desde un punto de vista más ampliado sobrepasa las fronteras del continente europeo. Como destacan diversos autores latinoamericanos (Dussel, 2000; Quijano, 2000; Lander, 2000; Mignolo, 2000), no se puede hablar de modernidad sin considerar las relaciones de poder constituidas a través de la colonialidad. Esta es la cara oculta, el otro lado silenciado y escondido de la modernidad.

Paralelamente, es esencial destacar que la palabra ocio es fuertemente cargada de connotaciones negativas en todos los países latinoamericanos de habla hispana (y de lengua portuguesa también, lo que en parte explica porqué en Brasil, por ejemplo, el concepto más difundido sea el de lazer). El ocio es, en general, visto como una amenaza para el desarrollo de las sociedades que pretenden modernizarse, progresar, desarrollarse y expandirse económicamente. Prevalece así la máxima "tiempo es dinero" y, de esa manera, no se puede perder tiempo con actividades consideradas inútiles e improductivas. Por lo anterior, postulamos que fue por estas razones que la palabra más difundida y legitimada en América Latina de habla hispana fue recreación, y no ocio, desconsiderando así los aspectos fundamentales que están en la base de las concepciones de cada uno de estos términos.

Además, en la actualidad el ocio y la recreación son, cada vez más, concebidos como mercancías direccionadas al consumo (alienado y alienante) de bienes y servicios, algo cada vez más necesarios para el logro y perpetuación del sistema neoliberal capitalista. De esta forma, al quedar el ocio en manos del mercado, como ocurre en muchos casos en las realidades latinoamericanas, este será comprendido casi exclusivamente como un nicho económico generador de lucro y al servicio de las economías, y no necesariamente como una forma de entregar una mayor calidad de vida a los seres humanos que acceden a este. Así, el ocio será entendido únicamente como otro objeto de consumo, perdiendo con esto su potencial capacidad de ser un aporte en la generación de otras perspectivas creativas y críticas, que permitan cambiar la mirada y hacer frente a las problemáticas sociales actuales de forma innovadora y renovada. Por esta vía, la relación que la ciudadanía establecerá con su propio ocio será pasiva, generando un consumo alienado, marcado por una fuerte tendencia escapista y sobreconsumidora (Elizalde, 2010).

En los últimos años, algunos autores latinoamericanos vienen intentando reconceptualizar y ampliar las comprensiones de ocio porque entienden que el concepto de recreación es limitado e insuficiente ya que, en muchos casos, remite a un simple activismo. Todo esto es válido, pero muchas 
veces genera confusiones e imprecisiones conceptuales entre el ocio y la recreación, provocando amplias polémicas entre estudiosos de estas temáticas en América Latina.

Como fue mencionado anteriormente, los conceptos son representaciones/abstracciones que expresan una visión parcial y no neutral de la realidad. Más allá de la búsqueda de objetividad, la perspectiva que se tenga de cualquier sistema o fenómeno real siempre estará mediada por la mirada del observador y condicionada, en parte, por su contexto. Ya que los conceptos no pueden ser tratados como absolutos y universales, es muy importante tener en cuenta no solamente las definiciones de recreación y de ocio que un determinado autor ocupa. También es fundamental reconocer desde donde nacen los conceptos, conocer y analizar los contextos en que fueron producidos, a que motivaciones responden, los valores que expresan, los fundamentos que los definen, las visiones de mundo e ideologías subyacentes, y los proyectos políticos de sociedad con que están comprometidos.

En el caso de América Latina este cuidado es fundamental porque, como es tratado en este artículo, en general los conceptos de recreación y de ocio más difundidos, entre los estudiosos de estas temáticas, están muy vinculados a las características y a los intereses que son propios de otras realidades. Recordamos que según la clasificación elaborada por Munné (1980) es posible identificar tres abordajes en la producción teórica sobre el ocio: (1) el abordaje empírico, de tradición norteamericana; (2) el abordaje teórico, que involucra teorías producidas sobre todo por estudiosos europeos y norteamericanos, y (3) el abordaje crítico, relacionado principalmente a los autores vinculados a la Escuela de Frankfurt. Munné clasifica todos estos abordajes como "burgueses". Propone, como alternativa, un abordaje que supere la visión burguesa desde una perspectiva dialéctica, basada sobre todo en las ideas de Marx.

Sin duda el esfuerzo del autor entrega interesantes aportes para los estudios sobre el ocio y el tiempo libre. Pero indirectamente coloca a Europa y a EE.UU. como centros de producción de conocimientos sobre esta temática. A su vez, desde esta comprensión, se corre el riego de que al resto del mundo, incluida Latinoamérica, solo le quedaría reproducir teorías generadas en otros contextos.

Obviamente, muchos conocimientos producidos en distintos países pueden ser útiles para ayudarnos a reflexionar sobre el ocio en nuestras realidades. Pero los conceptos no deben ser incorporados sin un posicionamiento crítico, evitando así la perpetuación de las redes invisibles de dominación, generando la colonialidad del poder y la colonialidad del saber, dos dispositivos que se encuentran emplazados "en una misma matriz genética" (Castro-Gómez, 2000: 6). Por lo cual es necesario entender y valorar la necesidad de resignificar, releer y reescribir con profunda atención los conceptos adoptados.

De este modo, los conceptos y teorías elaborados por autores de otros contextos y de otras épocas pueden ser interesantes cuando representan un punto de partida para nuevas lecturas, interpretaciones y resignificaciones contextualizadas y críticas. Es así que los conceptos de ocio y de recreación sistematizados en Latinoamérica y en otras realidades necesitan de permanentes diálogos más profundos y críticos con los desafíos sociales, políticos, históricos, económicos y ambientales, entre otros, presentes en cada cultura y cada sociedad.

\section{Ampliando la mirada sobre los conceptos de ocio y de recreación}

Una nueva mirada sobre los conceptos de ocio y de recreación en América Latina tiene que ser construida rescatando los profundos saberes y prácticas ya elaboradas en los territorios latinoamericanos. Considerando las culturas de los pueblos indígenas, de los grupos descendientes de África y de otros continentes del mundo, que son la base de la diversidad cultural y étnica de la región; las teorías históricas, sociales, ecológicas, (geo)políticas y pedagógicas que marcan el pensamiento crítico de autores latinoamericanos; la educación popular y los movimientos de base; las prácticas comunitarias de autogestión, la economía solidaria, así como tantas otras prácticas y experiencias de alternativas al sistema neoliberal capitalista desarrolladas con éxito en el contexto latinoamericano.

Lo importante es que muchas de estas prácticas están siendo desarrolladas en América Latina como alternativas concretas para superar las problemáticas existentes en esta región. ${ }^{3}$ Destacamos, de este modo, que existen otros caminos frente a un sistema que se pretende plantear como modelo único y universal. 
Latinoamérica es un mosaico de realidades marcado por la diversidad en varios sentidos, uno de ellos es el que en su cotidiano conviven las las lenguas indígenas, lenguas originarias de los colonizadores de Europa y las lenguas llamadas criollas. Por lo anterior creemos que, en un primer momento, lo más importante y medular no será la palabra que se utilice, ya que lo que realmente importa es la esencia de los conceptos, esto es, las perspectivas y visiones que ellos expresan.

A pesar de lo recién señalado, no podemos olvidar que los conceptos son nominados por una palabra específica, la cual también expresa, muchas veces, en su proceso de construcción etimológica, semántica, contextual, política, social, pedagógica y cultural algo más que un simple vocablo.

Consideramos necesario destacar de forma explícita que los conceptos de ocio y de recreación son distintos. Junto a lo anterior señalamos de forma abierta que tomamos, en este artículo, la opción de identificarnos con el concepto de ocio en cuanto una palabra que corresponde a los conceptos de lazer (portugués), leisure (inglés) y loisir (francés). Aclaramos que desde nuestro punto de vista el ocio no es reducido al inverso del trabajo, como un supuesto "no trabajo". El ocio representa, así, un campo con características propias. Desde esta interpretación, el ocio es más amplio que la recreación, pudiendo incluso incluirla en cuanto posibilidad de vivenciar actividades generalmente ligadas a la diversión.

Estas consideraciones exigen indagar y profundizar en que es lo que realmente queremos expresar con el concepto de "ocio". Según la interpretación aquí adoptada, en cuanto una práctica social contextualizada desde América Latina, el ocio necesita ser comprendido y reconocido como una dimensión de la cultura. De esta manera, cada pueblo y cada sociedad que compone la región latinoamericana construye y significa sus prácticas culturales, que son vividas como disfrute de la cultura y de la vida social en sus propias temporalidades. De esta forma, el ocio no está subyugado al trabajo industrial, a la urbanización, ni al capitalismo, como tampoco a la "modernidad".

Por lo anterior, la tradicional forma de conceptualizar al ocio únicamente en función del trabajo, como si fuera lo opuesto de este, necesita ser revisada. Esta no es la única posibilidad de entender y vivenciar el ocio. Es fundamental destacar que desde esta visión la existencia del ocio queda solo justificada a partir de las necesidades y intereses del trabajo. Según nuestra interpretación el ocio necesita ser conceptualizado y resignificado a partir de otras miradas y la perspectiva de la cultura nos parece ser un importante sendero desde donde empezar este nuevo camino de cambio. Desde aquí, entendemos que el ocio es una creación cultural y una práctica social compleja e históricamente determinada. Así entendido, el ocio no es un fenómeno aislado y se manifiesta en diferentes contextos según los sentidos y significados producidos/reproducidos culturalmente por las personas en sus relaciones con el mundo. El ocio participa de la compleja trama histórico-social que caracteriza la vida en sociedad, y es uno de los hilos tejidos en la red humana de significados, símbolos y significaciones.

En la vida cotidiana el ocio constituye relaciones dialógicas con otros campos además del trabajo, tales como la educación, la política, la economía, el lenguaje, la salud, el arte, la ciencia y la naturaleza, entre otras dimensiones de la vida, siendo parte integrante y constitutiva de cada sociedad. Reflejando las peculiaridades del contexto histórico y sociocultural en el cual es desarrollado, el ocio implica "producción" de cultura - en el sentido de la reproducción, construcción e transformación de prácticas culturales vivenciadas lúdicamente por personas, grupos, sociedades e instituciones.

De este modo, expresamos nuestra concepción de ocio como una dimensión de la cultura caracterizada por la vivencia lúdica de manifestaciones culturales en el tiempo/espacio social. Así, el ocio se constituye en la articulación de tres elementos fundamentales: la ludicidad, las manifestaciones culturales y el tiempo/espacio social. Juntos, estos elementos configuran las condiciones materiales y simbólicas, subjetivas y objetivas que pueden - o no- hacer del ocio un potente aliado en el proceso de transformación de nuestras sociedades, volviéndolas más humanas e inclusivas (Gomes, 2010).

Las manifestaciones culturales que constituyen el ocio son prácticas sociales vivenciadas como disfrute de la cultura, tales como: fiestas, juegos, paseos, viajes, música, poesía, grafiti y murales, pintura, escultura, danza, vivencias y expresiones corporales, fotografía, teatro, actividades comunitarias, ferias con nuevas modalidades de intercambio, actividades recreativas y deportivas, festivales y eventos artísticos, variadas modalidades de educación popular local, espacios de conversación y debate, entre muchas otras. Estas y otras manifestaciones poseen significados singulares para cada sujeto y para cada grupo humano. Constituyen prácticas inmemorables en la vida de cada persona y en la cultura de cada pueblo y pueden asumir múltiples significados: al ser concretizadas en un determinado tiempo/espacio 
social, al dialogar con un determinado contexto y, también, al asumir un papel peculiar para los sujetos, grupos sociales, instituciones y sociedad que las vivencian histórica, social y culturalmente.

No olvidemos que el ocio también comprende otras prácticas culturales enfocadas en posibilidades de introspección - tales como la meditación, la contemplación y el relajamiento- que pueden constituir significativas experiencias personales y sociales gracias a su potencial reflexivo. Por cierto, existe un prejuicio con este tipo de experiencia porque ellas desafían la lógica productivista que impera en nuestra realidad social, al ser entendidas como un hacer nada, cuando lamentablemente pasan a ser consideradas como improductivas y como una pérdida de tiempo. De lo cual definitivamente discrepamos ya que no todo en la vida humana deberá ser medido únicamente por la vara de la productividad, y además, con lo cual nos preguntamos ¿Productivo para quién? Más aún, incluso si estás prácticas culturales fuesen improductivas, cual es la necesidad apremiante de tener que serlo ¿A que intereses y a que valores responde esa preocupación por la productividad?

Entonces, entendido así, todo fenómeno cultural, incluido el ocio, expresará las peculiaridades del contexto histórico y social en el cual se desenvuelve en cuanto "producción cultural" -en el sentido de reproducción, reconstrucción y transformación de diversos contenidos culturales vivenciados por las personas, grupos e instituciones. Estas acciones serán construidas en un tiempo/espacio de producción humana, dialogando e influenciando y siendo influidas por las demás esferas de la vida en sociedad, lo que permitirá resignificar continuamente la cultura (Gomes, 2007).

A su vez, constatamos que no hay fronteras absolutas y rígidas entre trabajo y ocio, tampoco entre el ocio y las obligaciones cotidianas. Aunque el sujeto esté buscando satisfacción, más flexibilidad y libertad de elección a través del ocio, no siempre estará libre de obligaciones sociales, familiares, profesionales etc. Estos aspectos se mezclan en la vida cotidiana (Gomes, 2004).

Desde esta perspectiva, el ocio puede generar una experiencia de apertura marcada por una actitud que rompa y transgreda con lo permitido y con lo lícito, mostrándose muchas veces al borde de lo socialmente adecuado y aceptado. Justamente a esto se debe uno de los grandes temores, así como peligros que representa el ocio para el mantenimiento del status quo. De aquí surge, en parte, el intento de acallar y prohibir la disruptividad, contracorriente, alteridad e innovación subversiva, y todo aquello que pueden expresar un ocio problematizador, caótico, contrahegemónico y transformacional (Elizalde, 2010). Con esto, agregamos que el ocio, a su vez puede, permitir el desarrollo de una nueva identidad y de un sentido de pertenencia más abarcador.

Tenemos presente que las miradas sobre el ocio pueden ser diferentes ya que cada persona o investigador puede adoptar un punto de vista distinto para conceptualizarlo. Como fue mencionado, "ocio" es, generalmente, una palabra rechazada en toda América Latina. Al optar por este concepto, no se pretende reforzar o sobrevalorar los saberes y prácticas del ocio tales como son entendidos en otros países no americanos, por ejemplo España. Nuestra opción, en cambio, representa una acción comprometida con la resignificación y con la reconceptualización del ocio en los estudios sobre la temática en América Latina. Lo que tomamos como un desafío y como un proceso ya iniciado.

Con esto no pretendemos en ningún caso caer en un relativismo conceptual, pero si, abrirnos, como ya lo expresamos, a la posibilidad de multiplicidad de sentidos y comprensiones, que más que desvirtuar nuestro entendimiento, nos ayuden a ampliar las miradas. De este modo reconocemos que al igual que en los ecosistemas naturales, la diversidad humana es el mejor antídoto ante la muerte social y cultural (Elizalde, 2008). Esta muerte puede ser entendida como una homogenización de mentalidades al buscar que todos pensemos igual, no existiendo el reconocimiento de la valiosa riqueza presente en las diferencias y singularidades.

\section{Consideraciones finales}

Como fue señalado, tanto la naturaleza como el mundo construido por los seres humanos, incluidos los fenómenos concretos y abstractos, pueden ser (y de hecho son) traducidos en conceptos, que solo son interpretaciones y explicaciones de lo real. Frente a lo cual deberemos tener presente que todos los conceptos son solo construcciones humanas, por lo cual parciales y provisionales, factibles de perfección y en constante cambio, así como, con múltiples posibilidades de visiones y perspectivas diferentes, y con diversos niveles de profundización. 
Destacamos que será necesario tomar conciencia de que la mayoría de los entendimientos de ocio y de recreación conceptualizados y difundidos en América Latina fueron formulados en otros contextos, percibiendo que en general son insuficientes y en muchos casos inapropiados para la singularidad y diversidad cultural existente en las realidades latinoamericanas. Por lo tanto, corresponden a otras motivaciones y representan otras perspectivas que no necesariamente estarán centradas en las mismas problemáticas, contradicciones y potencialidades propias de América Latina.

Además, con mucho éxito, estas visiones procuran instituir un modelo único y homogenizante, lo que genera el mantenimiento de un orden instituido que muestra claros rasgos de exclusión y fragmentación social, así como variadas formas de pobrezas, que enfrentan y devastan amplias regiones del mundo, entre ellas las latinoamericanas.

Aclaramos de forma explícita que la opción por el concepto de ocio en América Latina se fundamenta en las siguientes razones:

- La recreación remite principalmente a actividades y en general está limitada a prácticas que no generan mayores reflexiones, lo que evidencia una dicotomía entre la teoría y la práctica.

- La recreación en cuanto práctica ha estado vinculada al recreacionismo y a la recreación dirigida, lo cual en muchos casos contribuye a mantener el status quo vigente en las sociedades latinoamericanas.

- En América Latina existen distorsiones en cuanto al uso del concepto de recreación, vinculándolo, por ejemplo, a las luchas obreras europeas del siglo XIX. Entendemos que el concepto de recreación en sus orígenes está relacionado al uso social y moralmente positivo del tiempo libre desde la transición del siglo XIX al XX. La recreación funcionó así como un potente dispositivo de control social en toda América frente al nuevo tiempo libre de la clase obrera, no correspondiendo necesariamente al derecho reivindicado y conquistado por los trabajadores europeos del siglo XIX.

- El ocio es más amplio que la recreación. Al ser el ocio entendido como una necesidad humana fundamental, la recreación pasa a ser uno de los posibles satisfactores de la necesidad de ocio. Por esto, el concepto de ocio puede abarcar a la recreación, lo que no ocurre de forma inversa.

- El ocio solo es aceptado cuando es útil a la lógica de producción y consumo capitalista. Generalmente es rechazado y visto como un vicio a ser combatido por que representa una amenaza al modelo de producción capitalista, que tiene la ética del trabajo como bien supremo. Potencialmente, el ocio puede confrontar el sistema vigente y justamente por esto por esto puede adquirir un carácter contrahegemónico.

- El ocio contrahegemónico puede estimular a las personas a reflexionar sobre sus vivencias y ayudar a valorizar las diversas manifestaciones culturales lúdicas, ya no solo aquellas que pueden ser compradas y vividas de forma pasiva y alienada como fuga de la rutina o como evasión. De este modo, las personas podrían desarrollar su capacidad crítica y cuestionadora a través del ocio.

Estas consideraciones resaltan la necesidad de promover una educación crítica/creativa por y para el ocio contrahegemónico y resignificado, una vez que este representa una posibilidad de reflexionar sobre la realidad en que vivimos y así poder aportar a las urgentes transformaciones que requieren las sociedades humanas para lograr ser participativas, incluyentes, equitativas, democráticas y justas. Por esto, el ocio no puede ser vistos como un antídoto para los problemas sociales cuyo objetivo sea simplemente aliviar las tensiones o compensar los dilemas que marcan profundamente el mundo actual (Gomes, Elizalde, 2009), sino solo como uno de los muchos elementos que posibilitará la construcción de sociedades realmente solidarias y sustentables.

Desde una perspectiva crítica, cuestionadora y contrahegemónica, el ocio es fundamental para hacer frente a los emergentes conflictos humanos-sociales y ambientales-ecológicos que aumentan cada día más, mostrando una real situación de "emergencia planetaria" (Elizalde, 2007, 2008). Es imprescindible destacar que entendido de esta forma, el ocio, puede estar comprometido con la búsqueda 
de alternativas desde una lógica contrahegemónica, que permita el reconocimiento, valoración y rescate de la diversidad cultural, elemento determinante si anhelamos sociedades donde sea posible el acceso a una vida buena para todos, los de hoy y los de mañana.

Tenemos la certeza de que las discusiones aquí realizadas no agotan el tema, por el contrario, lo dejan abierto para nuevas y futuras reflecciones. Todas estas ideas son tan solo algunas de las múltiples miradas que se pueden hacer en relación a la humanización y democratización del acceso de los sujetos de todas las edades, géneros, etnias y capas sociales a las oportunidades de ocio disponibles en sus realidades.

En este sentido, el desafío de revalorar, resignificar y reconceptualizar el ocio no se tratará de una nueva forma de adoctrinamiento o hegemonía gnoseológica y epistemológica. Siendo así, lo expuesto busca la producción de conocimientos nuevos que ayuden a conectar conceptos fragmentados y aislados, como una forma de volverlos coherentes y adecuados a las necesidades de la Latinoamérica actual. En este sentido, afirmamos que las teorías y conceptos responderán siempre a lo que entendemos por ser humano y a las utopías con que soñamos.

Finalizamos invitando a otros autores y estudiosos de estas temáticas a que continúen las reflexiones y análisis aquí iniciadas sobre los conceptos de ocio y de recreación, tanto en Latinoamérica, como en otras partes del mundo.

\section{Bibliografía}

Abbagnano, Nicola (1999), Dicionário de Filosofia. Martins Fontes, São Paulo.

Castro-Gómez, Santiago (2000), "Ciencias sociales, violencia epistémica y el problema de la 'invención del otro' ". En: Lander, Edgardo (comp.) La colonialidad del saber: eurocentrismo y ciencias sociales. Perspectivas Latinoamericanas. CLACSO, Consejo Latinoamericano de Ciencias Sociales, Buenos Aires. Disponible en: http://bibliotecavirtual.clacso.org.ar/ar/libros/lander/castro.rtf Acceso el 15/03/2010.

De Grazia, Sebastian (1966), Tiempo, trabajo e ocio. Tecnos, Madrid.

Diccionario Real Academia Española. Disponible en: http://www.rae.es Acceso el 7/4/2010.

Dumazedier, Joffre (1979), Sociologia empírica do lazer. Perspectiva, São Paulo.

Dussel, Enrique (2000), "Europa, modernidad y eurocentrismo". En: Lander, Edgardo (comp.) La colonialidad del saber: eurocentrismo y ciencias sociales. Perspectivas Latinoamericanas. CLACSO, Consejo Latinoamericano de Ciencias Sociales, Buenos Aires. Disponible en: http://bibliotecavirtual.clacso.org.ar/ar/libros/lander/dussel.rtf Acceso el 15/03/2010.

Elizalde, Rodrigo (2010), "Resignificación del ocio: Aportes para un aprendizaje transformacional". En: Revista Polis. $N^{o} 25$. Universidad Bolivariana, Santiago. Disponible en: http://www.revistapolis.cl/polis\%20final/25/art25.htm Acceso el 05/04/2010.

Idem (2008), El ocio entendido desde la teoría del desarrollo a escala humana: Buscando experiencias de aprendizajes para la transformación social. Funlibre, Colombia. Disponible en:

http://www.redcreacion.org/documentos/congreso10/RElizalde.html Acceso el 02/04/2010.

Idem (2007), "Responsabilidad Social Empresarial y gestión sustentable de recursos naturales". En: Wilson, Ronald y Caro, Pamela (org.), Sistematización Encuentro Nacional Ciudadanía y Responsabilidad Social Empresarial: Balance de experiencia y desafios de organizaciones de la Sociedad Civil. CICE, Santiago. p. 51-55. Disponible en:

http://www.ciceenlinea.cl/intranet/acolumna/documento_encuentro_final.pdf Acceso el 20/03/2010.

Ferreira, Aurélio B. H. (1999), Novo Aurélio século XXI - o dicionário da língua portuguesa. 3.ed. Nova Fronteira, Rio de Janeiro.

Galuch, Maria Terezinha B.; Sforni, Marta Sueli F. (2005), “Aprendizagem conceitual nas séries inicias do ensino fundamental". In II Segundo Congresso Internacional e VII Semana de Psicologia - Psicologia: Sociedade e Saberes em transformação, 2005, Maringá. ANAIS - II Segundo Congresso Internacional e VII Semana de Psicologia - Psicologia: Sociedade e Sabres em transformação. Universidade Estadual de Maringá, Maringá. v.1, p.1-12. 
Gomes, Christianne (2010), "O lazer como campo mobilizador de experiências interculturais revolucionárias e sua contribuição para uma educação transformadora". En: Dalben, Ângela; Diniz, Júlio; Leal, Leiva; Santos, Lucíola (Org.). Convergências e tensões no campo da formação e do trabalho docente: Currículo; Ensino de Educação Física; Ensino de Geografia; Ensino de História; Escola, Família e Comunidade. Autêntica Editora, Brasil. p.284-310. (Coleção Didática e prática de ensino)

Idem (2008), Lazer, Trabalho e Educação: relações históricas, questões contemporâneas. 2. ed. (rev. ampl.). Editora UFMG, Belo Horizonte.

Idem (2007), "O ócio como objeto de estudos: Notas introdutórias sobre conceitos e ocorrência histórica em nossa sociedade". En: Cuadernos de Ocio y Sociedad. Corporación Civitas, Medellín. p.23-40. Nos 1-2.

Idem (2004), “L. Lazer - Concepções”. En: Gomes, C. (Org.). Dicionário crítico do lazer. Autêntica, Belo Horizonte. p.119-126.

Idem (2003), Significados de recreação e lazer no Brasil: Reflexões a partir da análise de experiências institucionais. Belo Horizonte: Faculdade de Educação da UFMG (Tesis, Doutorado en Educación), Belo Horizonte. Disponible en: http://www.eeffto.ufmg.br/celar/?main=biblioteca\&id=4 Acceso el 28/03/2010.

Gomes, Christianne; Elizalde, Rodrigo (2009), "Trabajo, tiempo libre y ocio en la contemporaneidad: Contradicciones y desafíos”. En: Revista Polis. $N^{o} 22$. Universidad Bolivariana, Santiago. Disponible en: http://www.revistapolis.cl/polis\%20final/22/art14.htm Acceso el 30/03/2010.

Gomes, Christianne; Osorio, Esperanza; Pinto, Leila M.; Elizalde, Rodrigo (Org) (2009), Lazer na América Latina/Tiempo libre, ocio y recreación en Latinoamérica. Editora UFMG, Belo Horizonte.

Gomes, Christianne; Pinto, Leila (2009), "O lazer no Brasil: Analisando práticas culturais cotidianas, acadêmicas e políticas / El ocio en Brasil: Análisis de prácticas culturales cotidianas, académicas y políticas". En: Gomes, Christianne; Osorio, Esperanza; Pinto, Leila; Elizalde, Rodrigo (Org.), Lazer na América Latina/Tiempo libre, ocio y recreación en Latinoamérica. Editora UFMG, Belo Horizonte. p.67-180.

Houaiss, Antônio e outros (2001), Dicionário Houaiss da língua portuguesa. Objetiva, Rio de Janeiro. Lander, Edgardo (2000), "Ciencias sociales: saberes coloniales y eurocéntrico". En: Lander, Edgardo (comp.) La colonialidad del saber: eurocentrismo y ciencias sociales. Perspectivas Latinoamericanas. CLACSO, Consejo Latinoamericano de Ciencias Sociales, Buenos Aires. Disponible en: http://bibliotecavirtual.clacso.org.ar/ar/libros/lander/lander1.rtf Acceso el 12/03/2010.

Mignolo, Walter (2000), "La colonialidad a lo largo y a lo ancho: el hemisferio occidental en el horizonte colonial de la modernidad". En: Lander, Edgardo (comp.), La colonialidad del saber: eurocentrismo y ciencias sociales. Perspectivas Latinoamericanas. CLACSO, Consejo Latinoamericano de Ciencias Sociales, Buenos Aires. Disponible en: http://bibliotecavirtual.clacso.org.ar/ar/libros/lander/mignolo.rtf Acceso el $30 / 03 / 2010$.

Morin, Edgar (1988), El método: El conocimiento del conocimiento. Cátedra, Madrid.

Munné, Frederic (1980), Psicosociologia del tiempo libre: Un enfoque crítico. Trilhas, México.

Osorio, Esperanza (2009), “La recreación en Colombia: Un campo en construcción”. En: Gomes, Christianne; Osorio, Esperanza; Pinto, Leila M.; Elizalde, Rodrigo (Organizadores), Lazer na América Latina/Tiempo libre, ocio y recreación en Latinoamérica. Editora UFMG, Belo Horizonte. p.217-252.

Quijano, Aníbal (2000), "Colonialidad del poder, eurocentrismo y América Latina”. En: Lander, Edgardo (comp.), La colonialidad del saber: eurocentrismo y ciencias sociales. Perspectivas Latinoamericanas. CLACSO, Consejo Latinoamericano de Ciencias Sociales, Buenos Aires. Disponible en: http://bibliotecavirtual.clacso.org.ar/ar/libros/lander/quijano.rtf Acceso el 17/03/2010.

Reid, Andrés; Leiva, Roberto; Elizalde, Rodrigo (2009), "La recreación en Chile: Una mirada desde la actualidad y la precariedad". En: Gomes, Christianne; Osorio, Esperanza; Pinto, Leila M.; Elizalde, Rodrigo. (Orgs), Lazer na América Latina/Tiempo libre, ocio y recreación en Latinoamérica. Editora UFMG, Belo Horizonte. p.181-216.

Requixa, Renato (1997), O lazer no Brasil. Brasiliense, São Paulo.

Suárez, Silvana (2009), "Una aproximación de la representación social de la recreación en Argentina: Aportes para resignificar el concepto". En: Gomes, Christianne; Osorio, Esperanza; Pinto, Leila; Elizalde, Rodrigo 
(Orgs), Lazer na América Latina/Tiempo libre, ocio y recreación en Latinoamérica. Editora UFMG, Belo Horizonte. p.41-66.

\section{Notas}

*Grupo de investigación OTIUM: Lazer, Brasil \& América Latina, Belo Horizonte, Brasil. E-mail: roelizalde@gmail.com

** Universidade Federal de Minas Gerais (UFMG), Belo Horizonte, Brasil. E-mail: chrislucegomes@gmail.com

${ }^{1}$ Todos estos países son, hoy, independientes de Reino Unido pero tienen el inglés como lengua oficial: Antigua y Barbuda (independiente desde 1981), Bahamas (desde 1973), Barbados (1966), Belize (1981); Dominica (1978), Granada (1974), Jamaica (1962), Santa Lúcia (1979) San Cristóbal y Nevis (1983), San Vicente y Granadinas (1979), Trinidad y Tobago (1962), Guyana (1966). La existencia de casi todos estes países aún es ignorada en todo el mundo. Suriname es un país latinoamericano que se tornó independiente de los Países bajos en 1975 y tiene el neerlandes como lengua oficial. Pero aún no tenemos ningún indicio de como (y si) la temática es tratada allá.

${ }^{2}$ Tienen el francés como lengua oficial: Haití (independiente desde 1804), Guayana Francesa (Departemento de ultra mar de Francia).

${ }^{3}$ Algunas de las principales características de las naciones latinoamericanas son: existencia de variadas formas de pobrezas y violencias; estar endeudados con la banca mundial; con dependencia económica hacia los países ricos del primer mundo; marcados por grandes desigualdades sociales y por una creciente concentración del poder económico y político; con estilos de vida cada día más consumistas, racistas, clasistas, arribistas, machistas; etc. Si señala algunos de los muchos desafíos pendientes es para no olvidar quienes somos, donde vivimos y que es lo que necesitamos modificar. 